Europe's Journal of Psychology, 7(1), pp. 99-111

www.ejop.org

\title{
Effect of perceived inequality and perceived job insecurity on fraudulent intent of bank employees in Nigeria
}

\author{
Owolabi Ademola Benjamin \\ University of Ado-Ekiti, Nigeria
}

Babalola Sunday Samson

University of Ibadan, Nigeria

\begin{abstract}
This paper examines the effect of perceived inequality and perceived job insecurity on fraudulent intent of bank employees in Nigeria. A total of 170 participants were used for the study. They were selected from five branches of commercial banks in Ado-Ekiti, Ekiti state, Nigeria. Perceived inequality was measured using the perceived inequality in work scale (Corey and Keyes, 1998), while perceived job insecurity was measured using the job insecurity scale (Ashford et al., 1980). Fraudulent intent was measured using a self developed scale. Results reveal that perceived inequality and perceived job insecurity have a significant effect on employee fraudulent intent.
\end{abstract}

Keywords: job insecurity, inequality, fraudulent intention, bank employees, behaviour.

\section{Introduction}

There are several types of behaviour that employees engage in that are detrimental to the organisation. These behaviours have been given several names ranging from antisocial, dysfunctional to counterproductive behaviours. These are behaviours that bring or are intended to bring harm to an organisation, its employees, or stakeholders. They may include such acts as arson, blackmail, bribery, sabotage, theft, interpersonal violence and fraud (Giacalone and Greenberg 1997). Spector (1997) has presented a model of antisocial behaviours in which frustration is the center piece. He argued that when an employee is frustrated and dissatisfied with the job the tendency for antisocial behaviour increases. 
Antisocial behaviours in organisations has been given several names leading to many related constructs such as workplace aggression, revenge, organization retaliatory behaviour, counterproductive work behaviour, deviance, incivility, bullying and abuse etc. Important to note, the literature on this topic has revealed that not all such behaviours are counterproductive or dysfunctional.

Counterproductive work behaviour

Counterproductive work behaviour has been defined as any behaviour that violates organisational norms in a way that is harmful to either the organisation itself, to the members of the organisation, or to both (Robinson \& Bennett, 1995). Some of these behaviours include theft (Hollinger and Clark, 1983; Wimbush and Dalton, 1997), absenteeism (Johns, 1997), and various forms of aggression (Folger and Baron, 1996; Greenberg and Alge, 1998;).

Robinson and Bennett (1995) have developed a taxonomy of deviant workplace behaviour categorising interpersonal deviance and organisational deviance. From their point of view, organisational deviance includes a) forms of production deviance which are behaviours that violate organisational norms regarding the minimal quantity and quality of work to be accomplished and b) property deviance, which is defined as instances when employees acquire or damage the tangible property or assets of the work organisation without authorization and other behaviours such as stealing from the company and/or sabotaging equipment. Interpersonal deviance includes acts of political deviance, which are behaviours defined as social interaction that puts other individuals at a personal or political disadvantage.

According to Rotundo and Sackett (2002), there are three categories of job behaviours that contribute to overall job performance and these include task, citizenship and counterproductive behaviours. Of all these job behaviours, counterproductive behaviour has received the least attention

Perceived inequality

One of the variables that has the tendency to increase employee's antisocial behaviour is the perception of inequality. Equity theory (Adams, 1965) focuses on people's feelings of how fairly they have been treated in comparison with the treatment received by others. It is based on the belief that people evaluate their relationships at work the same way they evaluate buying and selling such that the value of goods must be equal to what is paid for them. 
Most exchanges involve a number of inputs and outputs. According to equity theory, people place weight on these various inputs and outputs according to how they perceive their importance. When the ratio of someone's total outcome to total input equals the perceived ratio of other people's total outcomes to total inputs there is equity. When there is an unequal comparison of ratio, the person experiences a sense of inequality. This perception may be an antecedent attitudinal variable for committing fraud within the organisation (Greenberg and Alge, 1998).

The perception of workplace discrimination or perceived inequality can be accounted for by two factors: first is the actual existence of inequality driving perception and second, the employee's awareness of his/her right and sensitivity to unfair treatment. Reskin (2000) argued that workplace discrimination or perceived inequality can be explain by social cognition theory. Social cognition theory asserts that individuals have the tendency to automatically and unconsciously classify others into two groups - in-group and out-group - and that based on this categorisation individual tends to make judgments about fairness or and the treatment they receive. Deitch et al. (2003) found that perception of inequality has significant personal and organisational consequences on workers' behaviour. Pavalko, Mossakowski and Hamilton (2003) reported in their United States study of sex discrimination at work that perceived inequality predicted both emotional and physical well-being of workers.

In an article entitled "Retaliation in the workplace: The role of distributive, procedural and international justice", Skarlicki and Floger (1997) investigated the relationship between organisational justice and retaliation behaviour. They discovered that when employees perceived inequality in workplace they tended to engage in retaliation behaviour. This is consistent with what equity theory suggests may lead to fraud intent.

Hollinger and Clark (1983) also discovered that when employees felt exploited by the organisation, they were more likely to engage in acts against the organisation, such as theft, as a mechanism to correct the perception of injustice. Similarly, Greenberg and Scott (1996) reported that employee theft was a reaction to underpayment inequity.

Perceived job insecurity

Another variable that may lead to counterproductive work behaviour such as fraud is the perception of job insecurity. Perceived job insecurity is the perception of employees about how secure their job is; this perception may or may not reflect the 
actual level of job security. Job insecurity is an employee's perception that his or her job is uncertain and may come to an end sooner than expected. From what has been theorised and inferred, it is understandable that job insecurity is highly threatening to employees given the prospect of losing the positive material, social, and psychological benefits associated with employment (De Witte, 1999). The notion that job insecurity may produce negative individual-level effects is well established in this period of economic meltdown when downsizing is occurring at an alarming rate.

Job insecurity among today's employees is not surprising given the competition that businesses endure and the intense pressures to remain profitable. One of the common means of reducing variable costs for organisations is via layoffs (Nixon, Hitt, Lee, \& Jeong, 2004). Each year millions of Nigeria workers are terminated by their employers to reduce costs (Bureau of Labor Statistics, 2006). This would be of little concern to firms except that 'surviving' employees usually react negatively to perceptions of job insecurity. This is particularly true in professional or managerial positions where strategic decision making has a great influence on organisational performance (Hitt, Bierman, Shimizu, \& Kochhar, 2001).

Human beings are naturally afraid of what tomorrow holds for them. The belief that the current job may not be available tomorrow creates the impression that each employee must prepare for the raining day to come. Research into job insecurity has offered consistent evidence across firms, industries, and countries that job insecurity is associated with negative employee attitudes and behaviours, and negative health outcomes (Sverke, Hellgren, \& Naswall, 2002). An attempt to secure tomorrow as a result of perceived job insecurity may be to engage in fraudulent activities, especially when employees also perceived unfair treatment from the organisation.

Fraudulent intent

Fraudulent practice is a behaviour that impacts negatively on the stability of an organisation but is highly rewarding for the individuals that perpetrate it. The Financial Training Centre (1990) defined fraud as the general manipulation or retention of information with criminal intent to deprive another party or parties of bonafide privileged, rights, or materials possessing.

The nature of fraudulent activities in the banking industry may appear a bit peculiar because of the nature of business operations in these institutions. This is especially so for banking organisations and other financial institutions. Because their business centres on money transaction, bank workers appear to have a high proneness to fraudulent activities. 
The types of fraud that are common to financial institution include sales fraud - this happens when there is an absence of credit control in an organisation giving rise to collusion between a customer and a staff member. It also includes the failure to raise dispatch documentation, thereby allowing goods out of the premises without authorisation, raising false credit notes or generating a reduction in customers' debt, as well as illegal access to cash receipts leading to teeming and laden.

Secondly, purchase fraud occurs as a result of improper control measure on authority for payment leading to false charge from suppliers with the connivance of an employee of the organisation, submission of false invoicing and representation of supporting document.

Other types of fraud include cheque payment fraud, which occurs when there are lapses in the control and security systems revolving around authorization and forgery. Cash payment fraud takes place mainly in the form of presenting fake supporting documents. Stock fraud occurs when there is an inadequate internal control system set in place and custody producers in the area of stock records. Finally, fixed assets fraud involves manipulation of records to conceal theft, premature scrapping of sales at below market value, converting of company assets for private purposes.

The types of fraud described above are not peculiar to banks alone, but extend to other organisations outside the financial sub-sector. Fraud could be a group affair as well as an individual act. When a group of people agrees to perpetrate fraud, different causal factors for involvement might be identified leading to different levels of involvement. Yet one person usually initiates the moved. Depending on the nature of constraint, others are likely to be co-opted to remove obstacles and also benefit from the eventual outcome. It can be presumed that if it were possible for the initiator and master minder to successfully execute fraud without hindrance from others, the individual might go ahead and do it alone. It thus would become an individual affair.

With the frightening distress fever that is going through the banking sector as a result of unwholesome behaviour of some bankers, increase in fraud committed through A.T.M. cards in conjunction with bankers and the impact that these may have on the economy, there is a pressing need to investigate factors that may make bank workers prone to fraud. 


\section{Methods}

Participants

A total of 170 participants were selected from five banks for the study, comprising 91 males $(53.5 \%)$ and 79 female (46.5\% of the subjects). Out of the toal numbers, 88 participants were single (51.7\%), while 77 (45.3\%) were married. Five (2.9\%) of the subjects were windows/widowers. 107 (62\%) of the participants were Christians, 57 (33.5\%) were Muslims while only $6(3.5 \%)$ belonged to other religions. In term of education qualification, 32 (12.9\%) had a qualification lower than B.Sc while 148 (87.1\%) were graduates (including ICAN, ACCA, MBA. M.SC).

Measures

Perceived inequality was measured using the Perceived Inequality in Work (PIWORK) Scale developed by Corey and Keyes (1998). This is a six item scale assessing core areas in the perception of individual workers about inequality at the workplace. The scale included Items such as "I feel cheated about the chances I have had to work on good jobs' 'I feel that others respect the work I do at my job' 'Most people have more rewarding jobs than I do'. The norm for the scale was constructed by considering the mean of the six items in the scale. The alpha value was of .78. An alpha coefficient of .65 was obtained for the revalidation of the scale on Nigerian population.

Job security was measured using the Job Insecurity Scale developed by Ashford et al (1980) based on the work of Greenhalgh and Rosenblatt (1984). The scale is divided into two subscales which include:

1. Threat: This subscale is intended to capture the individual's perceived total job treat. It consists of ten items relating to future possibility of job loss, retirement and re-employment. The threat subscale includes items such as 'I may lose my job and be moved to a lower level in the organisation', 'My service may no longer be needed and I might be laid off', 'I may lose my job and get fired';

2. Perceived powerlessness: This second subscale of job insecurity refers to employee's perceived powerlessness. It is a three item scale: 'I have power in this organisation to control events that affect my job', 'In this organisation I can prevent negative things coming out of from my work situation', 'I understand this organisation well enough to be able to control thing that affect me'. 
An alpha coefficient of .75 was reported by Ashford et al (1980) and the reliability was confirmed in a study conducted by Revert and yielded a standardised alpha of .71; finally, an alpha of .78 was obtained by Owolabi (2003) in a study using the Nigeria population.

Fraudulent intent was measured using a self developed scale. It is a 25 item scale with a Likert response ranging between 'strongly disagree' and 'strongly agree'. The scale includes items such as 'I am desperate to achieve my goal', 'If provoked, I will break the law', 'Stealing organisation property is a means of compensating for injustice'. Strongly disagree was scored 1 while strongly agree was scored 5; a higher score reflect greater fraudulent intentions. An alpha of.72 and split half reliability coefficient of .70 were reported for the scale.

Procedure

Five banks were randomly selected from among the banks in Ado-Ekiti, Ekiti State Nigeria. The banks will be refered to here as A, B, C, D, and E to avoid identification. The three scales were combined to form a single questionnaire which was distributed through the bank secretaries after establishing a rapport. Out of 200 distributed questionnaires, only 170 were properly filled and fit for data analysis. Due to the busy schedule of bankers it took a total of two weeks for the questionnaires to be totally retrieved back for data analysis.

\section{Results}

Data analyses were done using two statistical methods. First, analyses of variance were computed to test the effect of the two variables on fraudulent intent. Secondly, a t-test was computed to test for sex differences on both the independent and dependent variables. The mean scores were also computed to show the direction of the result.

Table 1: Mean scores for perceived inequality, perceived insecurity and fraudulent intent along banks

\begin{tabular}{|l|l|l|l|l|l|}
\hline Variable & Bank A & Bank B & Bank C & Bank D & Bank E \\
\hline Perceived inequality & 16.05 & 12 & 13.8 & 17.30 & 18.88 \\
\hline Perceived insecurity & 14.2 & 9.06 & 14.6 & 16.20 & 20.14 \\
\hline Fraudulent intent & 12.48 & 8.46 & 12.01 & 15.6 & 16.8 \\
\hline
\end{tabular}


Table 2: An ANOVA showing the effect of perceived inequality and perceived job insecurity on fraudulent intent of bank employees

\begin{tabular}{|l|l|l|l|l|l|}
\hline Variable & SS & DF & MS & F & $P$ \\
\hline PI (A) & 314.7 & 1 & 314.7 & 2.53 & $>.05$ \\
\hline $\mathrm{JI}(\mathrm{B})$ & 2741.7 & 1 & 2741.7 & 22.02 & $>.01$ \\
\hline $\mathrm{A} \times \mathrm{B}$ & 510.3 & 1 & 510.3 & 6.10 & $>.05$ \\
\hline Errol & 20168.23 & 164 & 124.49 & & \\
\hline Total & 26365.18 & 168 & & & \\
\hline
\end{tabular}

Key: $\mathrm{PI}=$ Perceived inequality; $\mathrm{JI}=$ Job insecurity

From Table 2 we can conclude that there is a significant main effect of perceived inequality on fraudulent intent (F 1,168 $=2.53$ P $>$.05) i.e. when employees perceive that they are not fairly treated the tendency to engage in fraudulent acts is high. It also revealed that perception of job insecurity has a significant main effect on fraudulent intent $(F 1,168=22.02 \mathrm{P}>.01)$. This means that the feeling that one's job is threatened is a factor that can lead people to fraudulent act. Finally, the results show the perceived inequality and perceived job insecurity have an interaction effect on fraudulent intent $(F 1,168=6.10 \mathrm{P}>.05)$.

Also, looking at the means in Table 1, the bank with the highest mean score for perceived inequality and perceived job insecurity (Bank E) also has the highest mean score for fraudulent intent. The bank with the least mean score for perceived insecurity (Bank B) also has the least mean score for fraudulent intent.

Table 3: Mean scores of perceived inequality, perceived insecurity and fraudulent intent classified by gender

\begin{tabular}{|l|l|l|l|l|l|}
\hline GENDER & INEQUALITY & INSECURITY & FRAUD INTENT & TOTAL & N \\
\hline MALE & 64.5 & 67.4 & 52.6 & 56.53 & 91 \\
\hline FEMALE & 60.6 & 65.5 & 68.7 & 41.6 & 79 \\
\hline
\end{tabular}

TABLE 4: Differences in perceived inequality, perceived job insecurity and fraudulent intent by gender

\begin{tabular}{|c|c|c|c|c|c|c|c|}
\hline & Sex & $\mathrm{N}$ & $x$ & SD & DF & $T$ & $P$ \\
\hline \multirow{2}{*}{$\begin{array}{l}\text { Perceived } \\
\text { inequality }\end{array}$} & Male & 91 & 64.5 & 11.66 & \multirow[t]{2}{*}{178} & \multirow[t]{2}{*}{1.76} & \multirow[t]{2}{*}{$>.05$} \\
\hline & Female & 79 & 60.6 & 13.19 & & & \\
\hline \multirow{2}{*}{$\begin{array}{l}\text { Perceived } \\
\text { insecurity }\end{array}$} & Male & 91 & 67.4 & 10.8 & \multirow[t]{2}{*}{178} & \multirow[t]{2}{*}{1.40} & \multirow[t]{2}{*}{$>.05$} \\
\hline & Female & 79 & 65.5 & 9.12 & & & \\
\hline \multirow{2}{*}{$\begin{array}{l}\text { Fraudulent } \\
\text { intent }\end{array}$} & Male & 91 & 36.7 & 6.88 & \multirow[t]{2}{*}{178} & \multirow[t]{2}{*}{1.10} & \multirow[t]{2}{*}{$>.05$} \\
\hline & Female & 79 & 32 & 5.92 & & & \\
\hline
\end{tabular}


From Table 4 presenting the results of independent t-tests, it becomes clear that there is no significant effect of gender on perceived inequality, perceived job insecurity and fraudulent intent of bank workers.

Table 5: Differences in fraudulent intent by age and tenure

\begin{tabular}{|l|l|l|l|l|l|l|l|}
\hline & Source & $\mathrm{N}$ & $\mathrm{X}$ & $\mathrm{St}$ & $\mathrm{df}$ & $\mathrm{t}$ & $\mathrm{P}$ \\
\hline \multirow{3}{*}{$\begin{array}{l}\text { Fraudulent } \\
\text { intent }\end{array}$} & Old & 56 & 42.68 & 4.62 & 168 & 4.36 & $>.05$ \\
\cline { 2 - 8 } & Young & 114 & 52.04 & 7.64 & & & \\
\cline { 2 - 8 } & Long tenure & 68 & 41.20 & 3.68 & 168 & 1.84 & $<.05$ \\
\cline { 2 - 5 } & Short tenure & 102 & 40.51 & 3.12 & & & \\
\hline
\end{tabular}

From the Table 5 it can be observed that there is a significant effect of age on fraudulent intent $t(168)=4.36 \mathrm{p}>.05)$; the mean score revealed that young employees (ages between 18 and 30) have greater fraudulent intent than older employees (ages between 31 and 60). The result also revealed that there is no significant effect of tenure on fraudulent intent.

\section{Discussion}

This study investigated the effect of perceived inequality and perceived job insecurity on fraudulent intent of bank employees. As it was hypothesised, when employee perceived that they are not fairly treated and also perceived that their job is not secured, the tendency to commit fraud increases. Employees generally have feelings and psychological needs which they expect the employer to help fulfilled. When they perceived that those needs are under treat or they feel that the organisation may not help in fulfilling these needs, it may results in employee directing their attention towards the fulfilment of such needs from other means including illegal ones.

Perceived inequality, for example may create feelings of rejection, feelings of worthlessness, feelings of not been valued. These feelings may reduce employee's commitment to the goals and aspirations of the organisation, thereby increasing the tendency to engage in fraudulent acts.

This result is convergent with that from the Haris and Benson (1998) study in which they examined the problems surrounding home thefts. In a survey research of six nursing homes, they found that factors like job dissatisfaction, perceived inequality and negative attitudes towards patients were increasing theft. Also Hollinger and Clark (1993) examined the contribution of organisational support to fraudulent intent 
in a survey of about 5000 people employed in three business sectors; they reported that when employees felt exploited by the organizations, they were more likely to engage in acts against the organisation such as theft as a mechanism to correct perceptions of injustice.

According to Goulder (1960), the norm of reciprocity obligates people to respond positively to favourable treatment and respond negatively to treatments that are not favourable. Roussan (1989) added that many employees believe that they and their organisation have a reciprocal obligation that exceeds formal responsibilities by both parties. This is reflects the belief that the 'psychological contract' between employee and firm will be respected. However, just as employees will reciprocate perceived fair exchange so they will also reciprocate unfair exchange.

It has been argued by Folger and Baron (1996) that if organisational decisions and managerial action are deemed unfair or unjust, the affected employees experience feelings of anger and resentment. This can elicit a desire for retribution and the dissatisfied employee experiences a need to punish those blamed for or perceived as the problem. One of the ways an employee might choice as a reaction to unjust treatment is, as we have argued here, by engaging in fraud. Work is central to human existence: it provides both social economic and psychological benefits. Any feeling or perception that suggests that employees' opportunity to work and satisfying those needs is threatened may not be received with calm resignation. It is on the basis of this that individuals who negotiate for jobs make haste to ascertain that its security is guaranteed. If there is a psychological feelings that the job is not secure, employees would likely make up for the expected lost.

Job loss connotes withdrawal of income. Unemployment rate is very high in Nigeria to the extent that there are graduates of five years who are still unemployed. Losing one's job definitely means staying unemployed for several months or years except if you are buoyant enough to start a business of your own. With this on the mind of an employee, job loss may mean staying unemployed for years. An employee whose job is under threat might want to increase savings for the period of unemployment; one of the easiest means of increasing savings for the raining day that is easily available to employees may be fraud.

Our results also revealed that age has a significant effect on fraudulent intent, with older employees showing lesser intention to commit fraud. This might be as a result of the fact that employees who are older believe that they have put in substantial number of years and feel the need not to lose their effort. It could also be that the number of years spent in the organisation might have increase the level of 
commitment of this set of employees. The young employees who are still full of a sense of adventure believe that they can take the risk and whatever happens there is still a long future ahead of them.

Obviously, both perceived inequality and perceived job insecurity yield insights into the dynamics of counterproductive work behaviours, especially organisational theft or fraudulent activities. It is therefore imperative for managers of organisations to pay critical attention to perceived inequality of treatment by workers and their sense of job insecurity so as to reduce the rate of counterproductive work behaviours, especially in the form of fraudulent activities within the organisation.

Limitations of the study

This study should be considered in light of several important limitations. First, the study would have benefited from the inclusion of other variables that may have significant effects on fraudulent intent. The two independent variables examined are not the only factors which may account for fraudulent intention. Second, the present sample was not representative of bankers in Nigeria, participants were only those who were willing to participate (convenience sampling). Third, the setting is in one state out of the thirty-six states in Nigeria and this limits the possibilities of generalising from the data. A fourth limitation is the reliance on self report measures which are vulnerable to social desirability effects and finally it is the intention to commit fraud that was measured and not actual fraud; intention may not totally predict behaviour.

\section{References}

Adams, J.S. (1965). Inequity in social exchange. In L. Berkowitz (Ed). Advance in experimental social psychological 2, (pp. 267-299). New York: Academic Press.

Ashford, S. Y., Lee, C. L and Bobko, P (1989). Content, causes and consequences of job insecurity: A theory-based measure and substantive test. Academy of Management Journal, 32, 803-829.

Blam, A. (1994). Psychology of works. The Dorsey press, Library of congress catalog No 84. 71212.

Deitch, E. A, Barsky A., Brief, A. P., Butz, R. M., Chan, S.Y. and Bradly, J. C (2003). Subtle yet significant: Everyday racial discrimination in the workplace. Human Relations, 
$56(11), 1299-1324$

De Witte, H. (1999). Job insecurity and psychological well-being: Review of the literature and exploration of some unresolved issues. European Journal of work and Organizational Psychology, 8, 155-177

Folger, R. and Baron, R. A. (1996). Violence and hostility at work: A model of reactions to perceived injustice. In G. R. VandenBos and E. Q. Bulatao (Eds.), Violence on the job: Identifying risks and developing solutions (pp. 51-85). Washington, DC: American Psychological Association.

Greenberg, E and Scoth, T. (1996). Equity and Justice in social behaviour. New York; Academic Press

Greenberg, J. and Alge, B. J. (1998). In R. W. Griffin, A. O'Leary Kelly, and J. Collins (Eds.), Dysfunctional behavior in organizations, Part A: Violent behaviors in organizations. Greenwich, CT: JAI.

Hampton, M. B and Heywood, J.S. (1993). Do workers accurately perceive gender wage discrimination. Industrial and Labour Relation Review, 47, 36-49

Hollinger, R. C. and Clark, J. P. (1983). Theft by employees. Lexington, MA: D. C. Health.

Johns, G. (1997). Contemporary research on absence from work: Correlates, causes, and consequences. In C. L. Cooper and I. T. Robertson (Eds.), International Review of Industrial and Organizational Psychology (pp. 115-174). London: Wiley.

Pavalko, E. K., Mossakowski, K., and Hamilton, V. (2003). Does perceived discrimination affect health? Longitudinal relationships between work discrimination and women's physical and emotional health. Journal of Health and Social Behaviours, 43, 18-33

Reskin, B. (2000). The proximate causes of employment discrimination. Contemporary Sociology, 29(2), 319- 328

Robinson, S. L., \& Bennett, R. J. (1995). A typology of deviant workplace behaviors: A multidimensional scaling study. Academy of Management Journal, 38(2), 555-572

Rousseau, S and Parks P (1963) Organization equity perception, employee job satisfaction and departmental absent and turnover rates. Organizational 
Behaviour and Human Performance, 24, 29-40.

Rotundo, M., \& Sackett, P. R. (2002). The relative importance of task, citizenship, and counterproductive performance to global ratings of job performance: A policycapturing approach. Journal of Applied Psychology, 87 (1), 66-80.

Skarlicki, D.P and Folger, R. (1997) Retaliation in the workplace: The role of distributive, procedural and interactional justice. Journal of Applied Psychology, $82,434-443$

Sullivian, V (1998). Management and Motivation. Penguin Books London.

Sverke, M., Hellgren, J. and Näswall, K. (2002). No security: A meta-analysis and review of job insecurity and its consequences. Journal of Occupational Health Psychology, 7, 242-264

Wimbush, J. C. and Dalton, D. R. (1997). Base rate for employee theft: Convergence of multiple methods. Journal of Applied Psychology, 82 (5), 756-763

About the authors:

Owolabi Ademola Benjamin, PhD, is an Industrial Organizational Psychologist and a Lecturer in department of Psychology, University of Ado Ekiti, Nigeria. His research interest is majorly in the area of organizational effectiveness and consumer behavior with special interest in advertising. He has published several articles in these areas both locally and internationally. He has also presented papers at international conferences bothering on the above mention area of Psychology. He is a member of the America Psychological Association.

Address for correspondence: Owolabi Ademola Benjamin, Department of Psychology, University of Ado Ekiti, Ekiti State, 5363, Nigeria

E-mail: labdem2005@yahoo.ca

Babalola Sunday Samson PhD is a senior lecturer in the Department of Psychology, University of Ibadan. As an Industrial Organizational Psychologist, his major area of interest is work attitude. He has published several articles in this area both locally and internationally. He has also presented papers at international conferences on work attitude. 